\title{
Hashtags and Hail to the Redskins: My Summer in Ashburn, Virginia
}

\author{
Madison Kemrite ${ }^{1 *}$
}

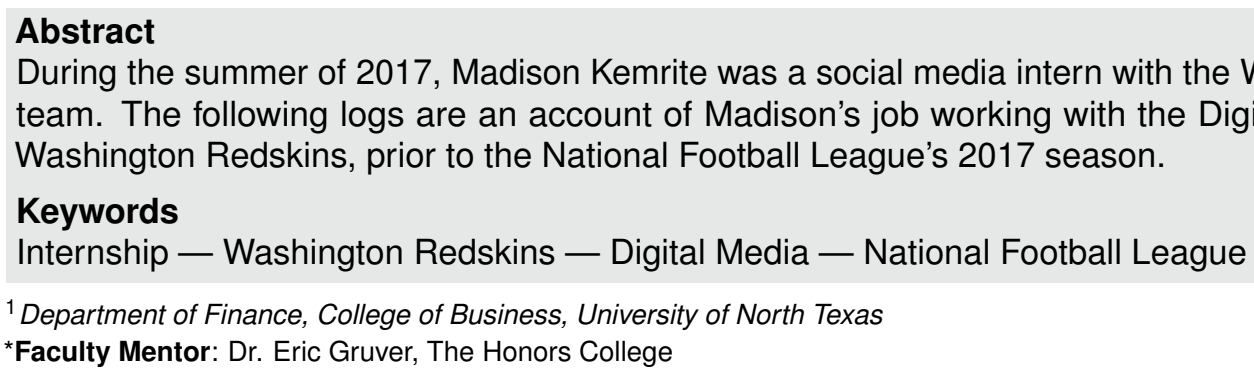

\section{Contents}

1 Daily Log

1.1 May ........................... Thursday May 23

1.2 June . . . . . . . . . . . . . . . . . 2 Friday, June $2 \bullet$ Monday, June $5 \bullet$ Tuesday, June $6 \bullet$ Friday, June 9 • Saturday, June $10 \bullet$ Monday, June $12 \bullet$ Tuesday, June $13 \bullet$ Tuesday, June 20 • Wednesday, June $21 \bullet$ Monday and Tuesday, June 26 and 27

1.3 July . . . . . . . . . . . . . . . . . . . . . 5 Tuesday, July $11 \bullet$ Monday, July $17 \bullet$ Tuesday, July $25 \bullet$ Thursday, July 27

2 Conclusion: August August $1 \bullet$ August 3

Author Biography

\section{Daily Log}

\subsection{May}

\subsubsection{Thursday, May 18}

Today was the first day of my internship and as much as I hate to admit it, I was really nervous. I think I underestimated how nerve wracking it would be to go to an area where I knew no one, drive to the offices of an NFL team, and introduce myself to supervisors and colleagues that I had never met. Since I tend to be independent and gravitate to new situations, I was not expecting to be as nervous as I was. The gravity of the situation really hit me when I walked through the front door and saw the Redskins' three Lombardi trophies sitting in a display case. I spent most of my first day doing paperwork with Human Resources and completing computer safety training. Even though there was not a lot of actual work that I had to do, meeting a lot of new people and trying to learn a lot of new computer software programs that I wasn't familiar with made it an overwhelming day. I was very impressed with my boss (the team's Digital Media and Content Supervisor) from the moment I met him. He always offers feedback and readily answered all my questions. I can already tell that this is going to be a very conducive environment for learning.

\subsubsection{Friday, May 19}

Even though today was only my second day, my boss and I hit the ground running. Instead of working from the office, we went to an elementary school in Maryland. This was my first time trying to navigate the roads of the DMV area, and although I made it to the school alive, I can already tell that driving here is a lot different than the Texas interstates that I have taken for granted my whole life. My boss and I were at the school to help publicize the Redskins Read Program which is put on by the organization's Charitable Foundation. The kids had won a reading competition that was against other elementary schools in the area. This victory warranted a surprise visit from several of the Redskins players. Seeing the reaction on the kid's faces when the players walked into the packed cafeteria was PRICELESS. After informing the kids that they had won the competition, the players delivered a bunch of brand new books that the Charitable Foundation had brought for the school. The players also held a touchdown dance competition with the kids, did some relay races, and then divided up into groups, broke out the new books, and read to the kids. It was so much fun to see these elementary school-aged kids huddled up around these big football players as they read to them. Not a bad way to spend my second day of work.

\subsubsection{Saturday, May 20}

Although I won't work every Saturday, today the Redskins Salute program participated in Playfield in the Park at West Potomac Park in Washington D.C. Redskins Salute is the official military appreciation club of the Washington Redskins and the first of its kind in the NFL. For Playfield in the Park, 


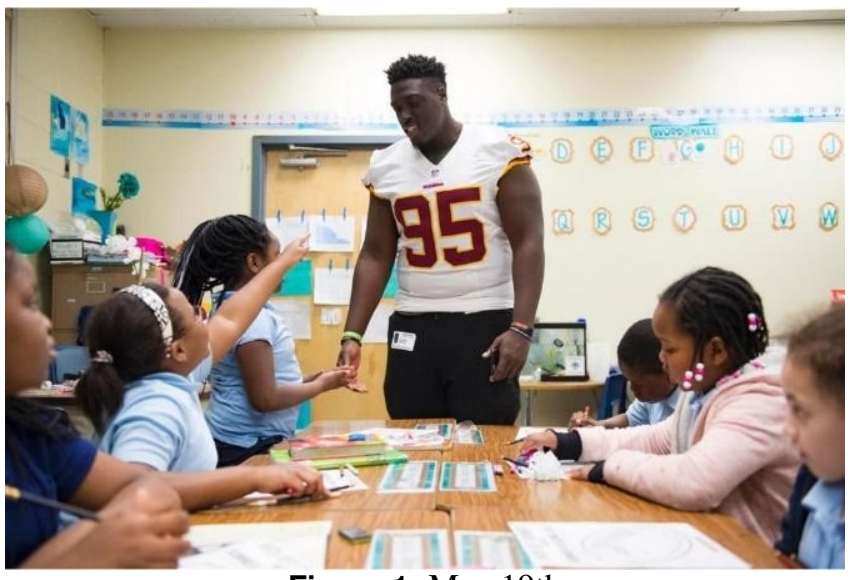

Figure 1. May 19th

Redskins Salute teams up with Yellow Ribbons United and several other organizations to help host a play day for kids and their families who have lost a loved one overseas. Some of the players, and even former players, came out and played in the park and had a picnic with the families. There was free food and ice cream, and lots of booths with games set up across the park.

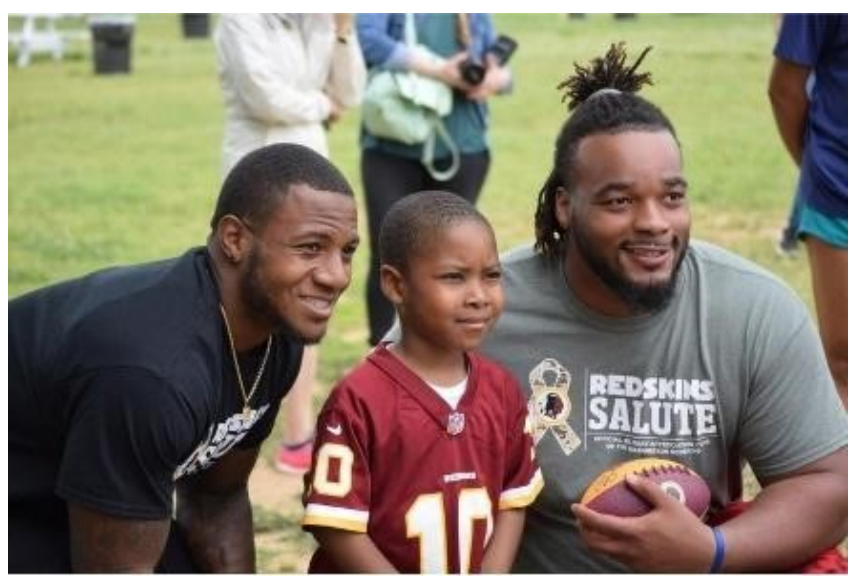

Figure 2. May 20th

Since no photographer from the team could make it to the event, I was responsible for taking pictures, some of which were published on Redskins.com. After the event, I stayed in the city, explored, and went to a few museums. Although I made a few mistakes, I think I finally have the D.C. metro system down and will be using it again in the future to cut down on the stress of driving in the city. (Pictured: two of the pictures that I took and that were published on Redskins.com)

\subsubsection{Wednesday, May 23}

This was the first media day of Organized Team Activities (OTAs) for the Redskins. This means that along with my daily responsibilities, I had the opportunity to go to practice, as well as Kirk Cousins' and head coach Jay Gruden's weekly press conferences. After having seen so many pressers such as these on TV, it was fun to be the one sitting in the seats

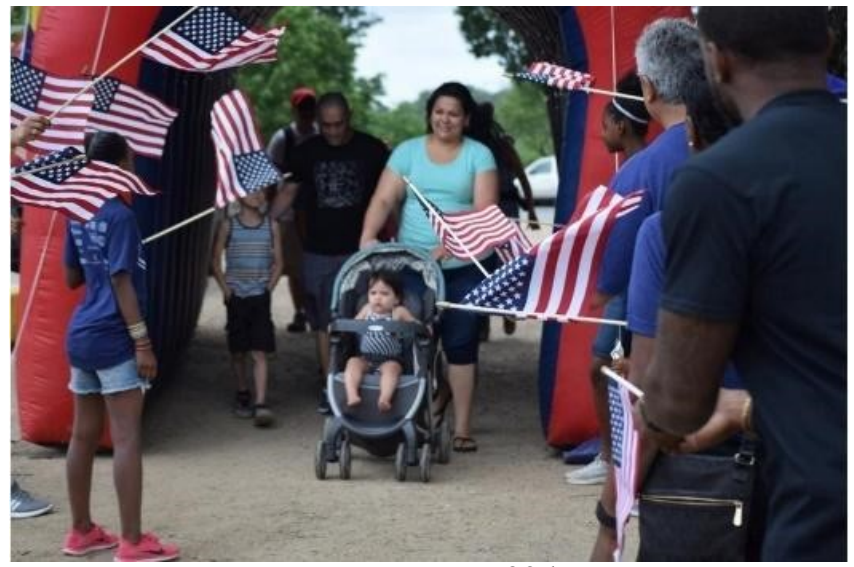

Figure 3. May 20th

watching live. For someone such as myself who has grown up watching and loving the sport, it was also a truly amazing experience to personally attend an NFL practice for the first time. Hopefully there will be many more to come. (Pictured: me very out of focus on the left side of the photo "next to" QB Kirk Cousins via Redskins.com).

\subsection{June}

\subsubsection{Friday, June 2}

I covered my first solo event today at the Redskins Play 60 Play Day. Since the play day was hosted at Redskins Park, my boss sent me over to Snapchat the event myself. Let's just say, it's a little different posting Snapchat stories when you know several thousand people are going to see it as opposed to the handful of views I get on my own personal account. Much like the Redskins Read Program, it was a lot of fun to watch the players interact with the kids. Since it was a Play 60 event, the kids went through different football-themed stations that were set up around the field and learned how to have fun and be fit. (Picture via Redskins.com)

\subsubsection{Monday, June 5}

A part that I love about my job, is that my department works with almost all other departments in the organization, which means I get to meet and interact with a lot of different people who work throughout the Washington Redskins. The social media department interacts regularly with the Digital, Marketing, and Public Relations Departments as well the Redskins Salute and Women of Washington fan clubs. This is really beneficial for me because it helps me see how the organization runs as a whole and how the different departments all work together.

\subsubsection{Tuesday, June 6}

This week was fun because our office started to really come together. As the social media intern, I work in the Newsroom with three other interns as well as four full-time staff members. Since there are eight of us who all work in the same room, half of which are new interns, the Newsroom has been a little quiet due to people not really knowing each other. This week 


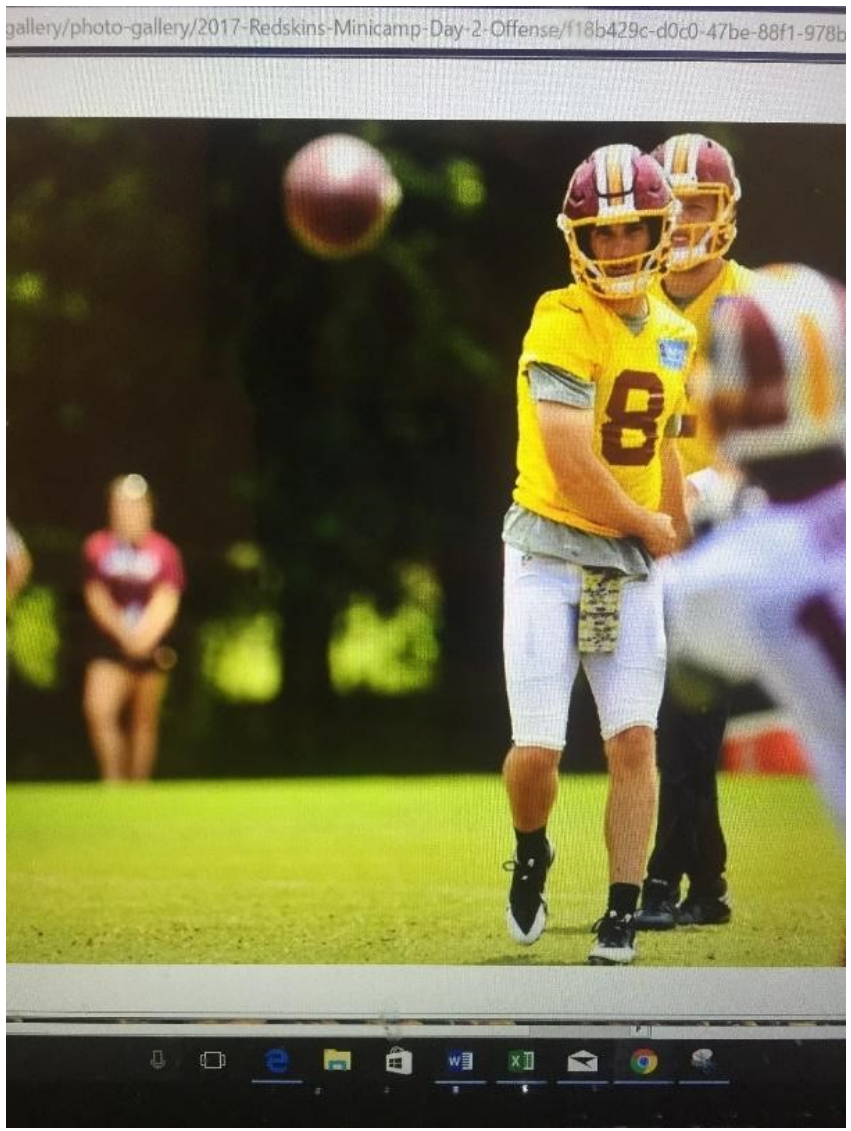

Figure 4. May 23rd

though, I am finding that the Newsroom is far from a quiet environment, and I love it. Everyone has their own dash of personality that they bring to the table, and I feel like we are starting to jell well as a group.

\subsubsection{Friday, June 9}

Today was probably my favorite thing that I have gotten to do since I arrived in Virginia (which is saying a lot). My boss let me tag along on a tour of Washington D.C. with all 19 of our rookie players. We started the day by going to a food bank in D.C. and packing bags of healthy food for kids who can't afford school lunches. After, we loaded up on a double decker bus and drove around to all the major monuments in D.C. Not only was it cool to be on a bus tour of our Nation's capital, but I got to do so surrounded by professional athletes. Afterwards, I rode the metro to the ballpark and met some of the other Redskins interns for the Washington Nationals' baseball game where we watched the Texas Rangers beat the Nationals (the other interns were less thrilled for the Ranger's victory than I was). I was wearing a UNT shirt at the ballpark and was stopped by a woman who graduated from UNT about 10 years ago. She was so excited to see a fellow member of the UNT family and I'm glad she stopped me to chat for a few minutes-it's always nice to see that the Mean Green family extends across the country.

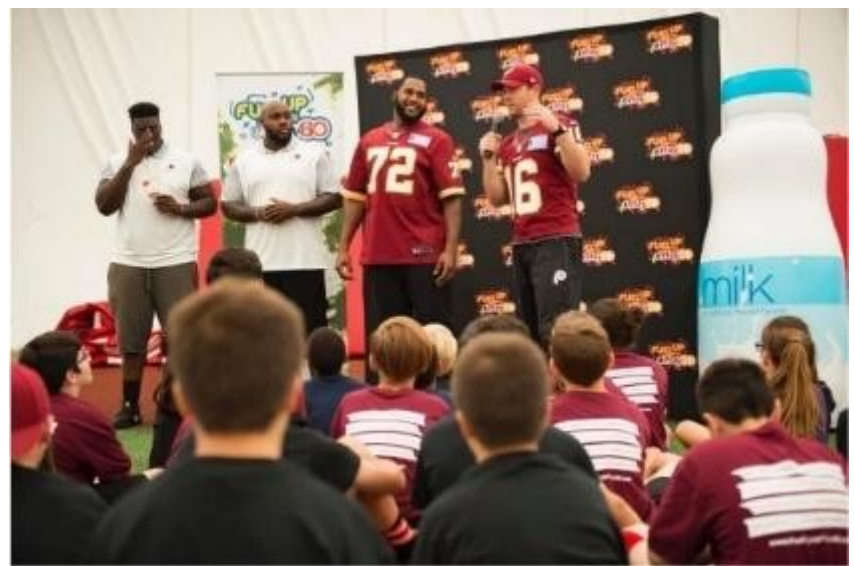

Figure 5. June 2nd

\subsubsection{Saturday, June 10}

If I told you that I spent the day at a polo match with Bob Marley's son Rohan and grandson Nico, would you believe me? Well, as crazy as that sounds, that's exactly what happened today! Allow me to explain. After graduating from Tulane, Bob Marley's grandson, Nico, was signed as an undrafted free agent by the Redskins. The Redskins content team thought that a charity polo match, attended by both Nico and his dad Rohan, would be a nice Father's Day piece for Redskins.com. Although I am not a journalist, my boss asked if I wanted to go just for the experience. I of course said yes, and accompanied one of our staff writers and his intern to the polo match. It was one of the coolest experiences I have had so far-even though I may have had to re-watch the polo scene in Pretty Woman to know what to wear.

The Marleys were such a gracious and welcoming family, with the perfect dash of that "Marley" flare that you would expect from the family of the reggae legend. I got to sit in on the hour-long interview with the Marley's of family stories, sage wisdom, laughs, and an explanation of the "lion order mentality" which is the zeal that the Marley's are famous for bringing to everything from the recording studio to the football field. Even though I was just there to observe, I didn't let my social media skills go to waste. I took the picture that Nico posted on his Instagram account and Rohan left me with his phone for a little while, instructing me to caption the photo that he posted. In the midst of all this "work," I also gained some valuable networking experience. Needless to say, a college student's budget rarely affords for opportunities to attend polo matches with successful business men and women. I talked to a few people and even reached out to one women the next day via LinkedIn, and she told me to keep in touch and she would keep me in mind for future internships. All in all, today was not a bad way to spend a Saturday.

\subsubsection{Monday, June 12}

Today I was lucky enough to be able to carry the excitement from the weekend into Monday. Instead of working in the office today, my boss and I went to the practice facility for the Redskins' player photo shoot. Throughout the day, about 30 


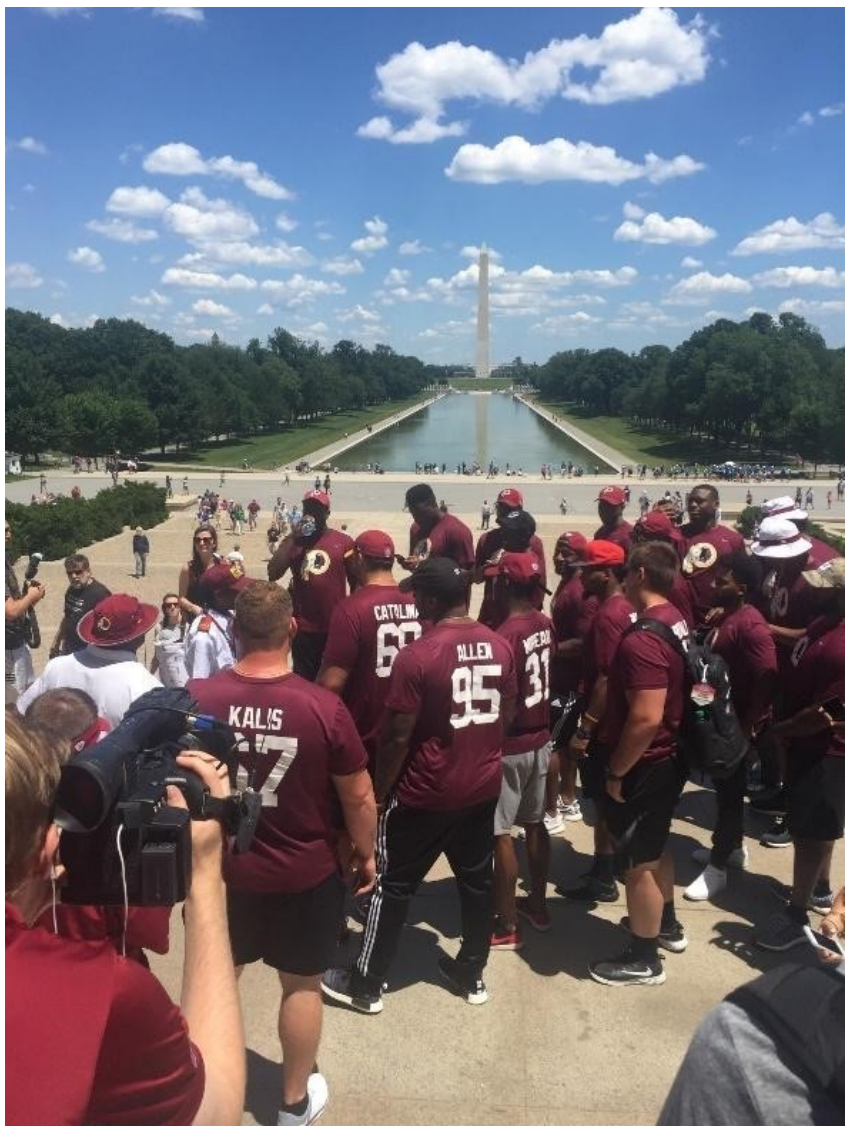

Figure 6. June 9th

of the team's top players, like Kirk Cousins, Ryan Kerrigan, and Josh Norman, came and took photos that will be used for things such as graphics and tickets throughout the season. Although there wasn't much I could do besides run the Snapchat a few times and observe, it was still an amazing experience (Pictured: me "photobombing" on the far left hand side of the photo via Redskins.com).

\subsubsection{Tuesday, June 13}

This morning I got to attend the press conference where the team announced that they would be promoting Doug Williams to VP of Player Personnel. Although I have sat in on press conferences before, this was special because the Redskins' President Bruce Allen was there along with the other Redskins executives. Today also marked the beginning of minicamp-one of the best parts of this being that I can wear shorts and a t-shirt instead of business casual (silly I know, but a business wardrobe has been difficult to adjust to for someone who can typically be found in workout clothes). Minicamp is also one of the only two days a year that the coaches are required to speak to the media-defensive coaches today and offensive coaches tomorrow. The Redskins' Senior Writer asked if I could help during these interviews and record them so we could transcribe them and extract quotes for future articles. However, no one came over immediately to interview the coach I was assigned to record. My boss had instructed me

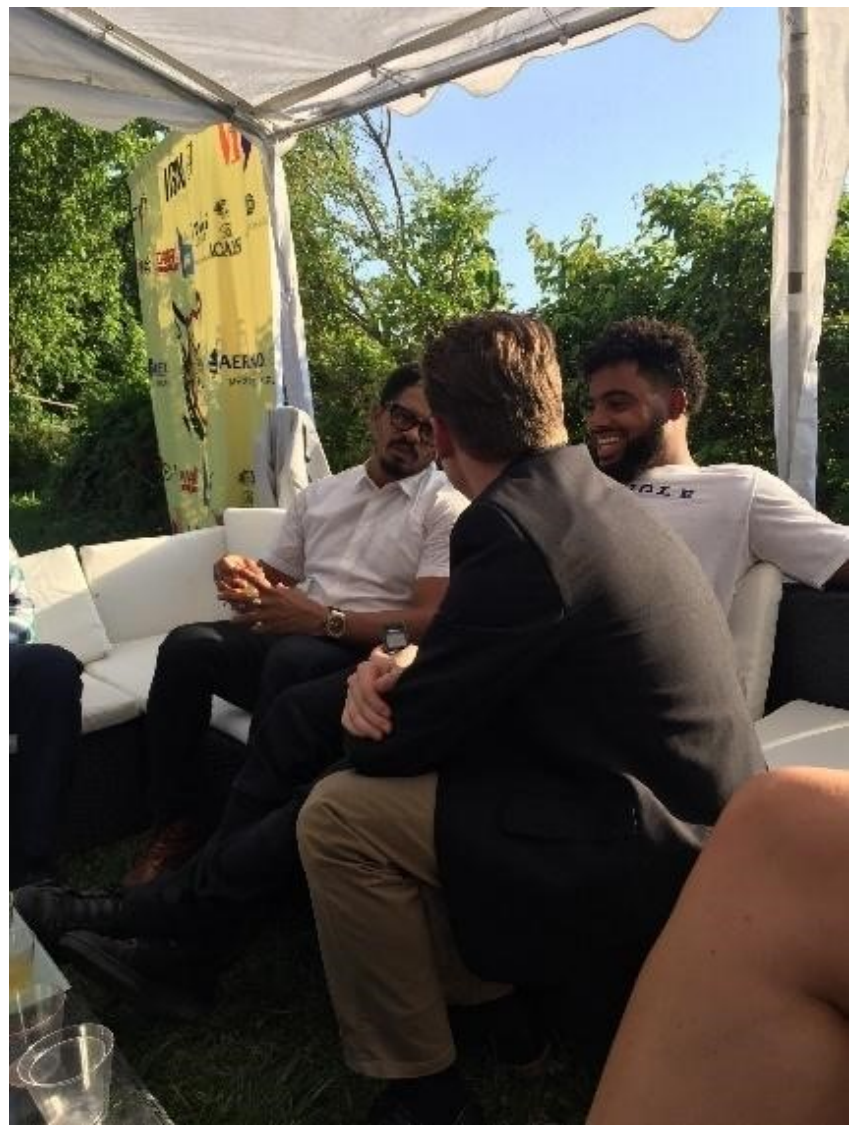

Figure 7. June 10th

that if this happened, I was to conduct the interview myself. So, without time to get nervous, I performed my first NFL interview with the Washington Redskins' Inside Linebackers coach. I really enjoyed it, and my boss even snapped a picture of the moment.

\subsubsection{Tuesday, June 20}

This year is the Redskins' 85 th anniversary. In celebration, the team is running an 85th anniversary Hall of Fans competition. For this competition, fans can submit pictures of themselves and describe why they deserve to be in the Redskins Hall of Fans by posting on various social media outlets using \#AllHail or submitting through the Redskins website. One of my duties this summer is sorting through these submissions. Before they are displayed on the website, I go through the submissions and take out the ones that are inappropriate or simply off topic. This was probably one of the more entertaining daily tasks I had. It was a lot fun to scroll through and see the stories of fans who are not only spread across the country, but across the world. It helps someone like myself, who didn't grow up watching the Redskins, get a feel for the history and passion behind the organization.

\subsubsection{Wednesday, June 21}

Today after work, I played in the annual employee flag football game. We went to the indoor practice facility, divided into teams and were given jerseys. I represented my UNT 


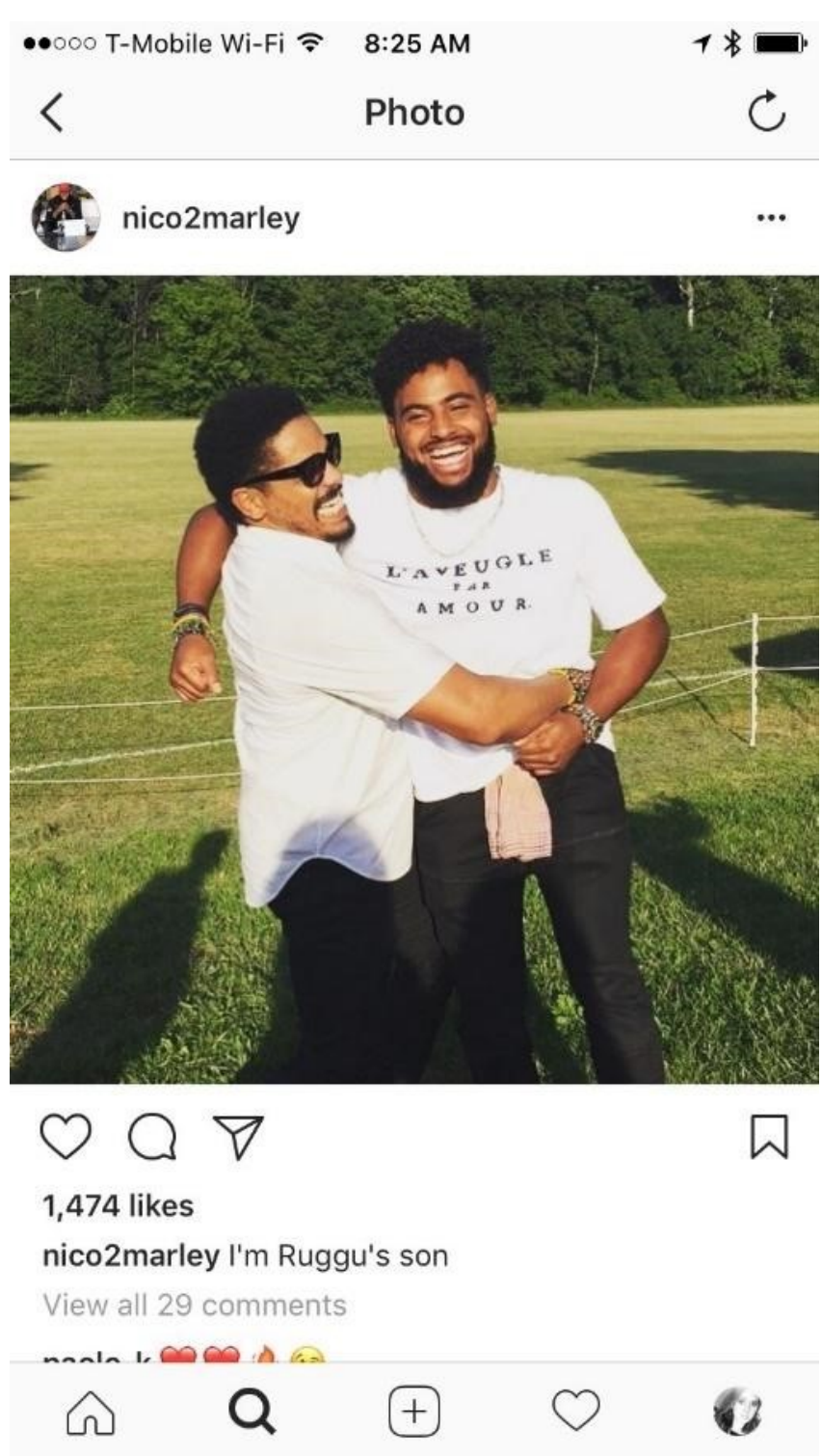

Figure 8. June 10th

intramural team well catching the first pass of the game, as well as scoring in the 2nd half. Super Bowl XXII MVP Doug Williams, who works in the team's front office, was at the game watching. I think it's neat that someone so high-up in the organization stayed after work just to watch an employee flag football game. (Pictured: my flag football team a.k.a., the winning team).

\subsubsection{Monday and Tuesday, June 26 and 27}

One of my responsibilities is finding and preparing fan photos that are posted on Facebook daily. Each morning, the Redskins will post a photo of a fan, or group of fans, who are 'repping' the Redskins in their daily lives. Finding and captioning these fan photos was one of my responsibilities during my internship. The main way that I find these photos is by searching hashtags on Instagram. I go to a database and search either \#HTTR or \#Redskins. Next, I go through

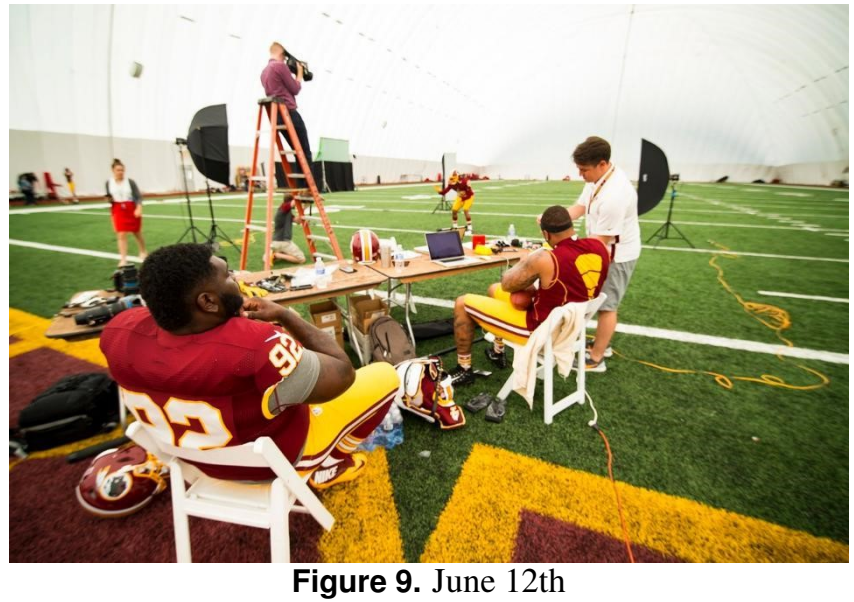

and request rights to the photos that fit the criteria. After the owner grants the team rights to use it, I crop them and caption them to be set to post daily. (Pictured: fan photo I captioned via Washington Redskins Facebook).

\subsection{July}

\subsubsection{Tuesday, July 11}

Throughout the summer, the writing interns and the staff writers have been putting together the annual Redskins yearbook that will be sold at training camp and today was the big day of editing. It was 'all hands-on deck' in the Newsroom to get the entire 172 page yearbook edited. It took me around 6 or 7 hours to read through and edit it, and then I had to stay and finish my other responsibilities. Although it may have been a long and tedious task, I'm glad I got to be a part of it and I even get my name listed in the yearbook as one of the editors.

\subsubsection{Monday, July 17}

Today was memorable for several reasons. First, it was the franchise tag deadline for the Redskins' quarterback Kirk Cousins. By today, the quarterback and team could come to a new contract agreement or the quarterback would play the 2017 season on the franchise tag. It was announced today that Cousins would play on the franchise tag. Although this really didn't change my daily responsibilities, it was a great learning experience to see the Newsroom in action as they quickly adapted to the news. Today was also memorable because it was my 21 st birthday. I celebrated in style by taking my car to the shop and then single handedly eating a whole pint of ice cream. Cheers to adult life I suppose.

\subsubsection{Tuesday, July 25}

Today is my last day in the office and then it's off to training camp for a week before heading back to Texas. We only worked a half day since everyone is heading to Richmond, VA for training camp. Although my internship is technically over and my boss's new intern is coming to training camp, I decided to attend camp for a few days and experience the excitement for myself. After work, I went to D.C. to say my "goodbyes" with a good friend I made this summer (she was 


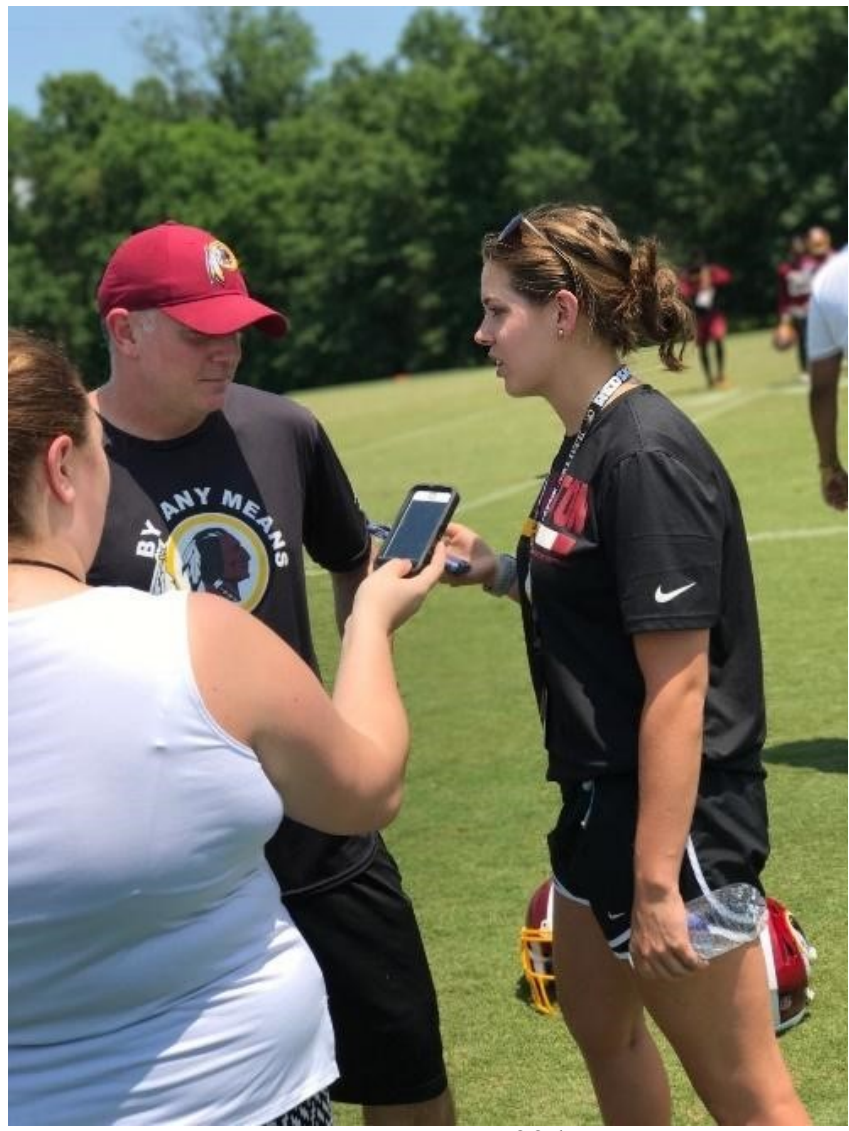

Figure 10. June 20th

even kind enough to pose in front of the Texas portion of the WWII Memorial with me). I have learned so much through this experience, but I am beyond excited for training camp to start.

\subsubsection{Thursday, July 27}

Today is the day. My first day at training camp. I am not even sure it's necessary to say, but I love it! Two press conferences a day, two hours of football practice a day, and tons of dedicated fans cheering on the Redskins. Instead of my normal responsibilities, I am spending camp just helping wherever I can and helping train my boss's new intern. The day flew by so quickly and I am really glad that I decided to come.

\section{Conclusion: August}

\subsubsection{August 1}

My internship may be coming to a close, but my experiences sure aren't. Today, my boss asked me to interview the Redskins punter Tress Way about the board game he created and just released on Kickstarter. I interviewed him for about 6 minutes, which in hindsight might have been a bit long, but he was very gracious and answered all my questions. After interviewing him, I was then informed that I was going to write the story about the new board game myself. Although I wouldn't consider myself a journalist by any means, I had a

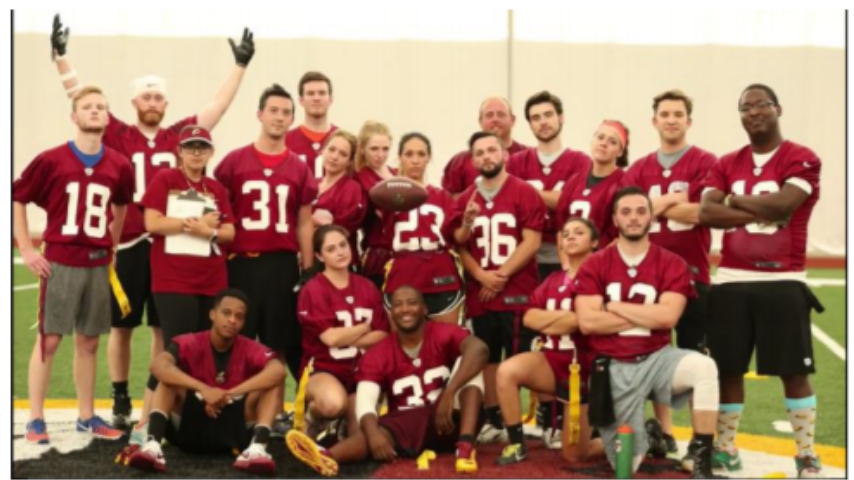

Figure 11. June 21st

lot of fun writing the article and getting my first byline.

\subsubsection{August 3}

My final day as an intern for the Washington Redskins. Wow, what an amazing experience it has been! I honestly don't want to leave. Everyone who I have worked with has become like family to me and have really gone out of their way to make "the Texas kid" feel welcome and this internship unforgettable. I can't believe how different I feel now than when I first got to Virginia. The nerves have faded into confidence and the apprehension has turned into true connections with a lot of fantastic people. It is hard to put into words everything I have seen, done, and learned in such a short time. I have made so many new friends, new connections, and have experienced so many new things (I may or may not already be planning my return visit). I am excited to bring back everything I have learned to UNT, and I am so excited to see where my career takes me next!

\section{Author Biography}

Madison Kemrite is from Conroe, Texas. She is studying Finance with a minor in Spanish, and is going to graduate in May 2019. She plans to work in the business or player personnel side of professional football. 


.

\section{P}

Washington Redskins

Yesterday at 8:50 AM - 8

Well, that's going to be a problem when they get older. \#HTTR

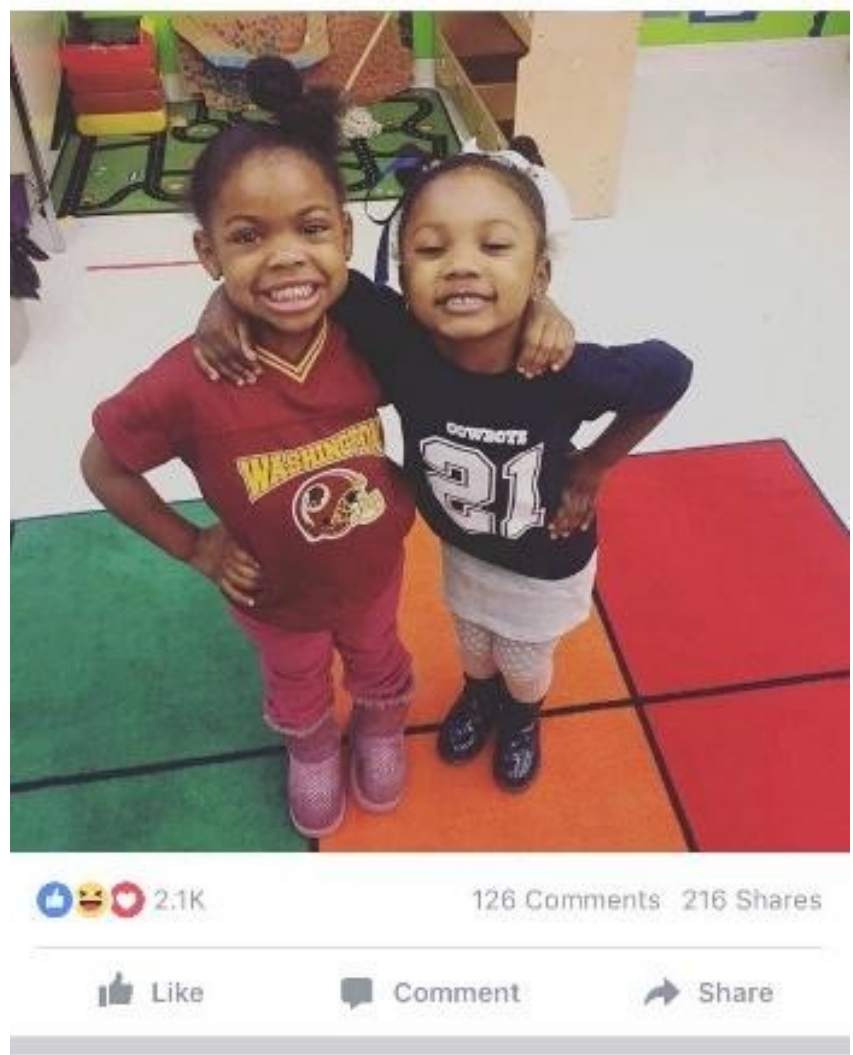

Lauren Olivia Smith liked this.

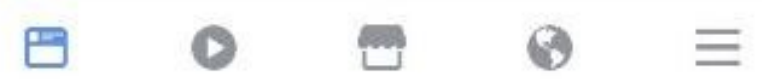

Figure 12. June 26th

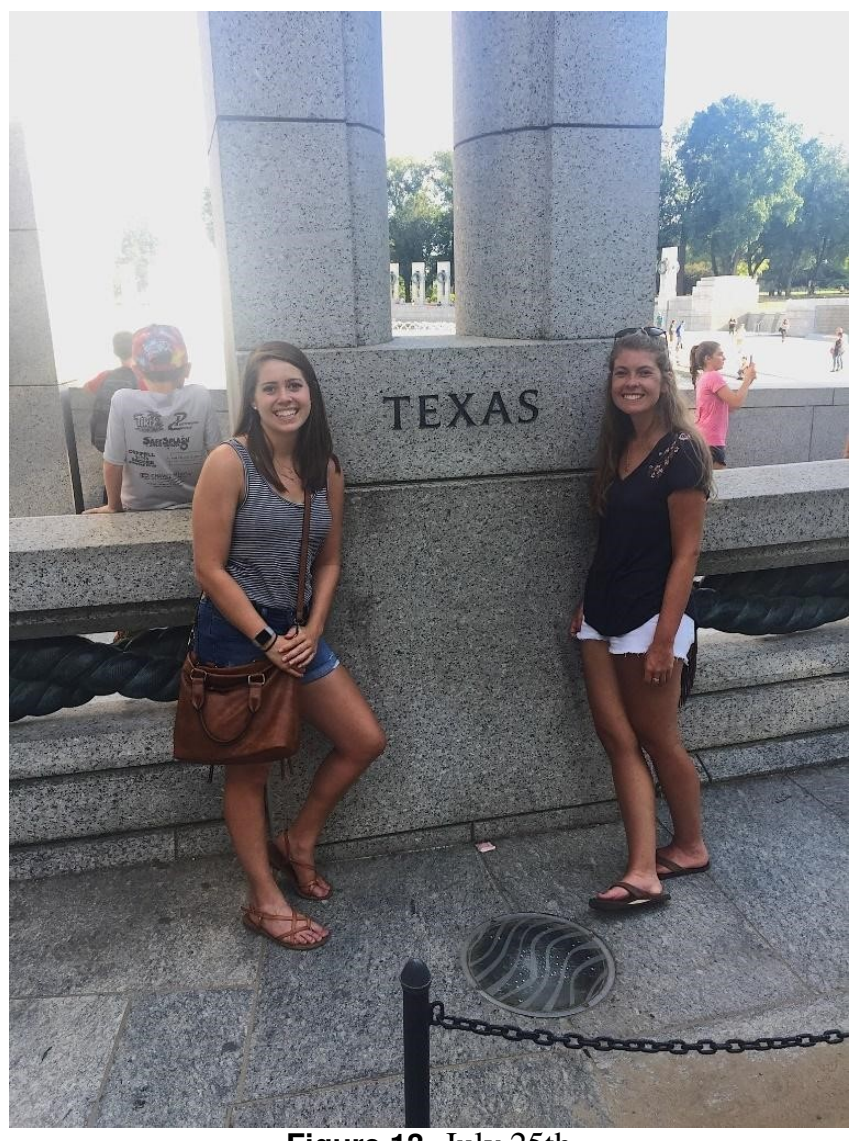

Figure 13. July 25th 


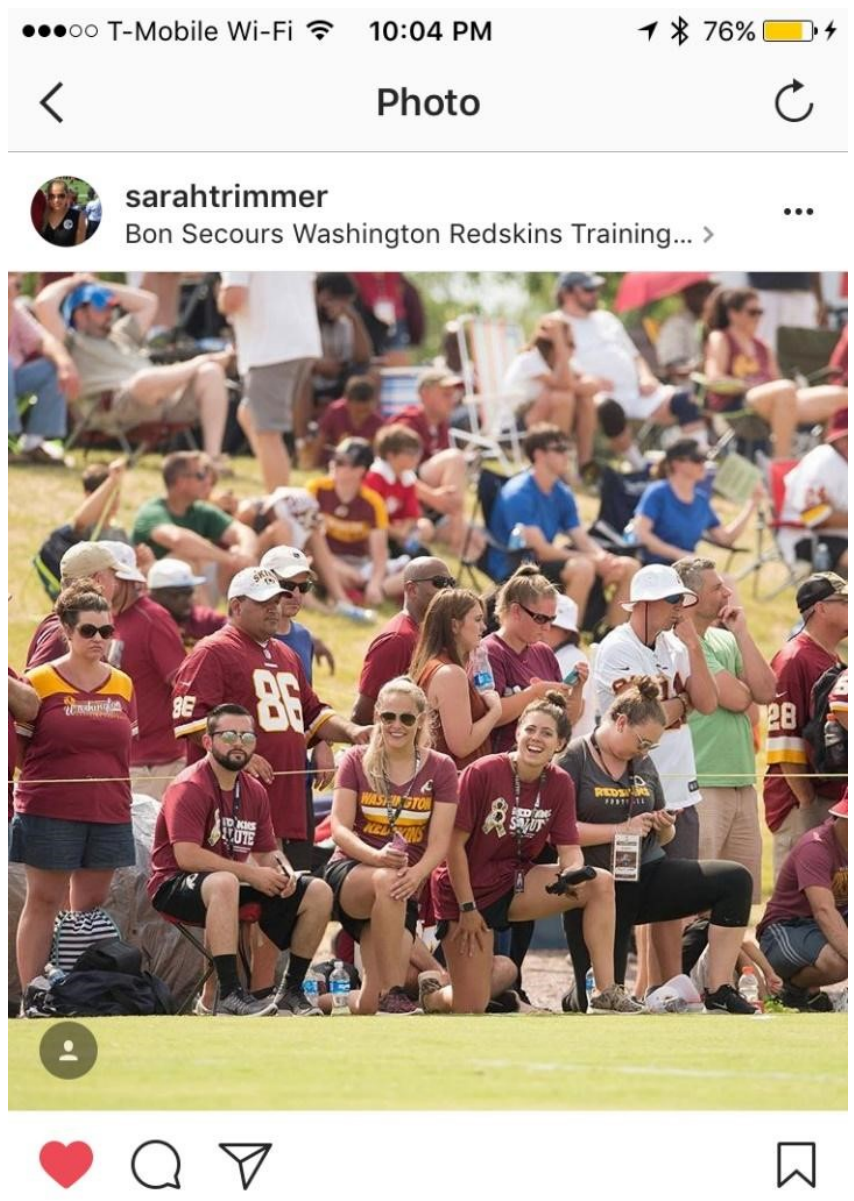

162 likes

sarahtrimmer \#skinscamp Day 7 with the Content Gawd \#stillblessed // (Photo creds: @redskinsphotog)

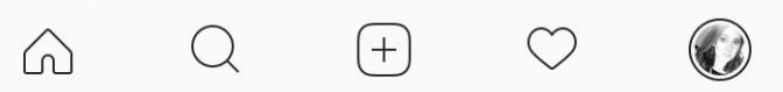

Figure 14. July 27 th 


\section{Tress Way Kicks Off New Venture With What's Your Bid Trivia Game}

Posted Aug 2, 2017 